\title{
Response to letter to editor 'What to choose in proximal hypospadias repair: onlay Island flap or tabularized preputial flap?'
}

\author{
Fang Chen ${ }^{1}$ (D)
}

Received: 11 June 2019 / Accepted: 13 June 2019 / Published online: 25 June 2019

(C) Springer Nature B.V. 2019

\section{Editor,}

We appreciate the manuscript entitled 'What to choose in proximal hypospadias repair: Onlay Island flap or tabularized preputial flap?' written by Dr. Acimi regarding our study of the comparison between Onlay and Duckett.

The writer states some experience and understanding about the Onlay urethroplasty on patients treated for proximal hypospadias with curvature of the penis, and we agree with most of his points. Both retrospective and prospective studies on long-term result of the hypospadias patients showed that those who underwent the approach with preservation of the urethral plaque were more likely to present the curvature recurrence. However, we must point out that most of these should be attributed to the improper choice of the surgeons. In fact, we prefer Duckett to Onlay when the curvature is more than $20^{\circ}$ after degloving. In our study, the curvature was $30.77^{\circ} \pm 9.97^{\circ}$ (Duckett) vs. $4.57^{\circ} \pm 8.15^{\circ}$ (Onlay) after degloving. Although we do not have long-term results yet, we can hope that the rate of curvature recurrence in our Onlay group will be low.
Fang Chen

doctorchenfang@126.com

1 Urology Department, Shanghai Children's Hospital, No.355, Luding Rd., Putuo District, Shanghai, China
The writer also argued that the time of our catheterization was longer than necessary. We tried to remove the tube in 7 days, but the result seemed unsatisfactory, most patients suffered dysuria and dribbling which may be caused by edema of neo-urethra, and the symptoms would relieve after 5-7 days re-catheterized. We suppose that is possibly due to the idiosyncracy in Chinese people. In addition, in Duckett group, the catheterization time should be even longer.

Finally, we use the modified Duckett approach in our study, which preserve both the proximal and distal urethral plate after it was transected, so that the island flap can cover on urethral plate at both ends, and this will reduce the incidence of urethral stricture. That is why we transect the urethral plate at the point of the maximal curvature.

Publisher's Note Springer Nature remains neutral with regard to jurisdictional claims in published maps and institutional affiliations. 